\title{
ESTIMATION OF STATE OF CHARGE OF LITHIUM-ION BATTERY BASED ON PHOTOVOLTAIC GENERATION ENERGY STORAGE SYSTEM
}

\author{
Ze Cheng, Li Wang, Jiguang Liu, Jikao Lv
}

Original scientific paper

The fast and accurate estimation of state of charge $(S O C)$ of lithium-ion battery is one of the key technologies of battery management system. In view of this nonlinear dynamic system of lithium battery, through the test and analysis of lithium-ion battery hysteresis characteristics, the second-order RC hysteresis model is established, and the cubature Kalman filter algorithm is used to estimate the battery state of charge in this report. The experiment results show that the battery model can essentially predict the dynamic hysteresis voltage behavior of the lithium-ion battery and cubature Kalman Filtering algorithm can maintain high accuracy in the estimation process.

Keywords: cubature Kalman filter; hysteresis model; Lithium-ion battery; state of charge

Procjena stanja naboja litij-ion baterije na temelju sustava akumulacije energije proizvedene solarnim čelijama

Izvorni znanstveni članak Brza i točna procjena stanja naboja - state of charge (SOC) litij-ion baterije jedna je od ključnih tehnologija sustava za praćenje stanja baterije. Imajući u vidu nelinearni dinamički sustav litij baterije, u ovom je radu postavljen RC model histereze drugog reda ispitivanjem i analizom karakteristika histereze litij-ion baterije, a kubatura algoritma Kalmanovog filtra primijenjena je za procjenu stanja naboja baterije. Rezultati eksperimenta pokazuju da se modelom baterije može predvidjeti dinamičko ponašanje naboja histereze litij-ion baterije, a algoritmom kubature Kalmanovog filtriranja održati visoka točnost u postupku procjene.

Ključne riječi: kubatura Kalmanovog filtra; litij-ion baterija; model histereze; stanje naboja

\section{Introduction}

With environmental protection and energy saving issues increasing, prominent, lithium ion battery, due to its high energy density, high working voltage, long cycle life, no pollution, light weight, and small self-discharge [1], takes on a more significant role in the field of energy storage batteries. To take full advantage of the dynamic performance of the battery system and prevent battery overcharge, a battery management system is needed.

Reliable cell model is the premise condition of SOC accurate estimates. The accuracy of the model affects the precision of $S O C$ estimation. Hysteretic characteristics are one of the basic characteristics of lithium ion batteries. It refers to the fact that $O C V$ of battery during the charge process does not match the $O C V$ of the discharge process. In order to improve the precision of the equivalent model of a lithium-ion battery, hysteretic characteristics must be taken into account.

In recent publications several SOC estimation algorithms such as the open circuit voltage (OCV) method, Ampere-Hour integral method and Kalman filter (KF) method are presented $[2 \div 5]$. The $O C V$ method [2] needs a long rest time, so it cannot be utilized in real time applications. The Ampere-Hour integral algorithm however is the most simple and convenient one, but it requires a prior knowledge of initial SOC and suffers from accumulated errors from noise and measurement. $\mathrm{KF}$ method is proposed to solve the above problem in recent years, but it is only suitable for linear system [4]. The Extended Kalman Filter (EKF) [5] is a nonlinear method of the KF, which has been used particularly for systems with nonlinear dynamic models.

This paper proposes a model based on hysteretic characteristics [6] of lithium-ion battery, and uses Cubature Kalman Filter (CKF) algorithm [7] to estimate the $S O C$, which greatly reduces the model error and the algorithm error. The next part is experiment analysis of battery hysteresis characteristics and its influence. In part III, we propose a high-precision battery hysteresis model which takes the hysteresis effect into consideration. Part IV introduces the volume Kalman filtering algorithm in the SOC estimation. In part $\mathrm{V}$, the hysteresis model is verified by experiments and CKF method is used to estimate the accuracy of $S O C$. Part VI summarizes the article.

\section{Experiment analyses of Lithium ion battery hysteretic characteristics}

The test of the hysteretic characteristics during the charge and discharge process has been done to show how the hysteretic characteristics affect the SOC estimation. The LP2770102AC lithium-ion battery, which is a lithium iron phosphate battery that can be used in portable high power devices, grid stabilization energy storage, and electric vehicles, has been chosen. Its capacity is $12,5 \mathrm{Ah}$ and nominal voltage is $3,3 \mathrm{~V}$. A Digatron MCT 30-05-40 cell cycler was used to test. The battery temperature should be kept at $20 \pm 2{ }^{\circ} \mathrm{C}$. The battery voltage is assumed to keep stable value after standing for 1 hour in the charging and discharging test process [8].

\subsection{The major loop of the hysteretic characteristics}

The major loop of the hysteretic characteristics is the $O C V$-SOC characteristic curve in one complete battery $S O C$ cycle [9]. Fig. 1 shows the testing process. The process of charging and discharging time is about 53 hours, and sampling time is 1 second. It can be seen the $O C V$ changes greatly when the $S O C<10 \%$ and $S O C>90$ $\%$.

The major loop of the hysteretic characteristics curve 
and the difference curve can be drawn with the data in Fig. 1. As shown in Fig. 2, it can be seen the charging $O C V$ is always above the discharging $O C V$ in the same $S O C$.

After dividing the curve of (b) into three parts, the largest relative difference is:

$$
D_{m a}=\frac{D_{m r}}{O C V_{\max }-O C V_{\min }}
$$

where $D_{m r}$ represents the biggest absolute difference value of each part.

1) $\operatorname{SOC}<10 \%=0,16 \mathrm{~V}(S O C=2,5 \%)=15,23 \%$

2) $10 \%<S O C<90 \%=0,035 \mathrm{~V}(S O C=30 \%)=3,33$ $\%$

3) $\mathrm{SOC}>90 \%=0,03 \mathrm{~V}(S O C=97,5 \%)=2,8 \%$.

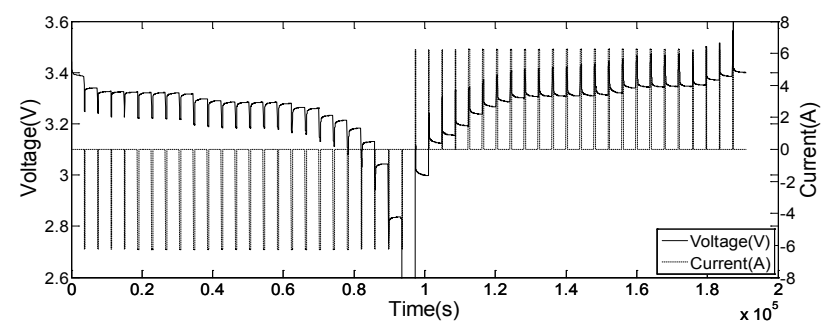

Figure 1 Voltage and current curve of hysteresis major loop

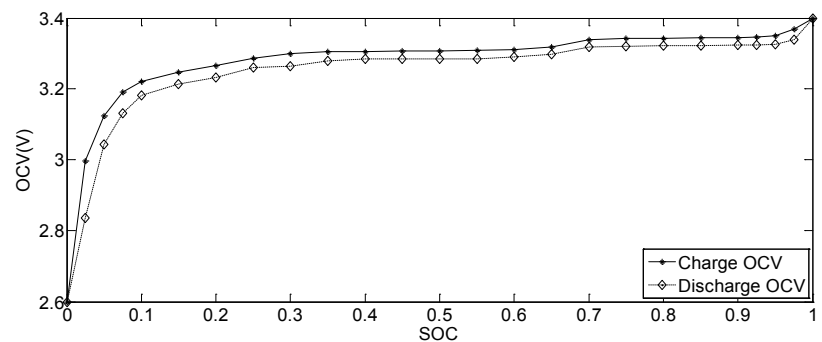

(a) SOC-OCV curve during charging and discharging

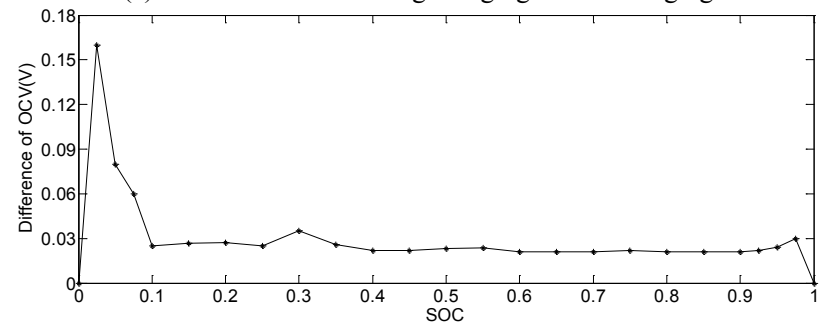

(b) $O C V$ difference curve

Figure 2 Hysteresis major loop characteristics

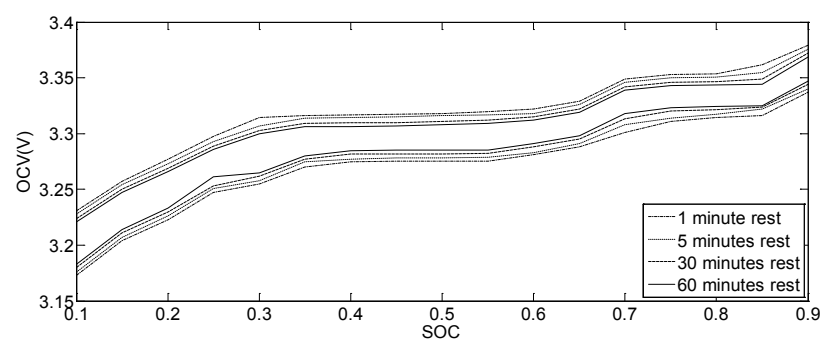

Figure 3 Hysteresis major loop characteristics with different rest time

The $O C V$-SOC curves are shown in Fig. 3 after varying different rest time to $1 \mathrm{~min}, 5 \mathrm{~min}, 30 \mathrm{~min}$. The curves show hysteretic characteristics are not only a function of $S O C$, but also a function of rest time [10]. As the rest time become longer, the hysteresis characteristics become weak, and then tend to be smooth ultimately.

\subsection{The minor loop of the hysteresis characteristics}

In practical applications of lithium-ion batteries, such as electric vehicle, lithium-ion battery is mainly working under the partial charge and discharge cycles [11]. Therefore minor loop of the hysteresis characteristics which is the battery $O C V-S O C$ curve under local $S O C$ cycle must be under considered in the battery $S O C$ estimation [12]. Fig. 4 shows the voltage and current curves in testing process.

Fig. 4 shows the minor loop of the hysteresis characteristics curve. As shown in Fig. 5, Black arrows represent the changing direction of SOC.

Experimental results show the following conclusion:

1) Hysteresis characteristic is a bunch of curve.

2) It is a history function of charging-discharging process.

3) It is a function of rest time.

4) The $O C V$-SOC curve of minor loop of hysteretic characteristics is always under the charging and discharging $O C V$-SOC curves of the major loop.

5) When the current changes direction, the $S O C-O C V$ trajectory also changes direction and successive approach to the major loop curves with the same direction $[13,14]$.

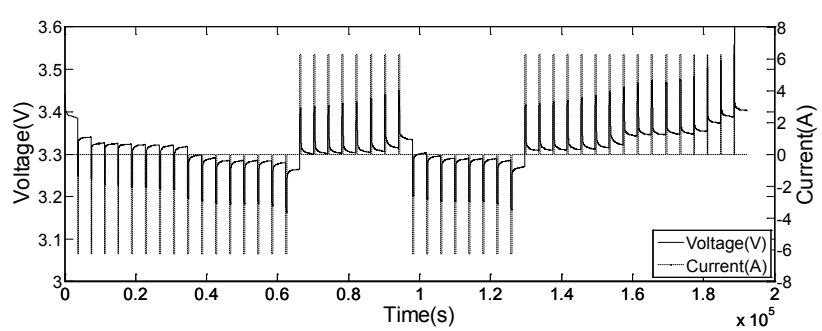

Figure 4 Voltage and current curve of hysteresis minor loop

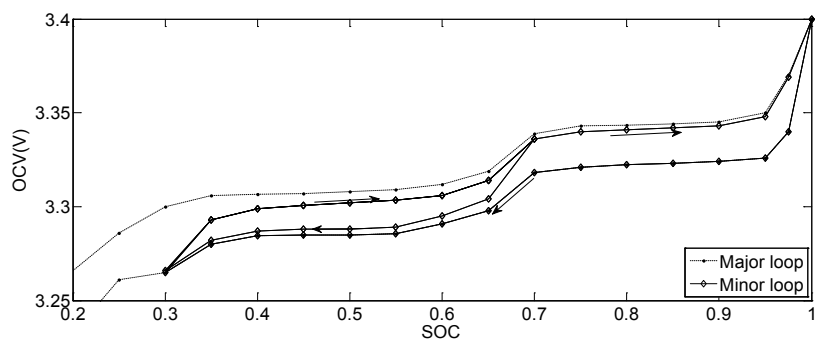

Figure 5 Hysteresis minor loop characteristics

\subsection{The influence of hysteretic characteristics to $S O C$ estimation}

SOC estimation error caused by the hysteresis characteristics is:

$$
E_{\text {SOC_Hys }}=\frac{S O C_{\text {Charge }}-S O C_{\text {Discharge }}}{S O C_{\max }-S O C_{\min }} \times 100 \% .
$$

By exchanging the axes of Fig. 2(a) and make a difference, the curve of $S O C-O C V$ and $S O C$ error curve are as shown in Fig. 6.

As can be seen from the Fig. 6(b), the maximum estimation error of $S O C$ caused by the hysteresis 
characteristics is $32,6 \%(O C V=3,3 \mathrm{~V})$, which means estimating the $S O C$ with the average of charging and discharging $O C V$-SOC curve will cause a big error. Battery $S O C$ is sensitive to the change of the $O C V$ especially in range of $10 \%$ to $90 \%$. Very small $O C V$ fluctuations are likely to cause a big SOC estimation error. Therefore the hysteresis characteristics must be taken into account.

\section{Lithium-ion battery equivalent circuit models}

Considering the accuracy, complexity and the requirements of different precision comprehensively, the battery model can be divided into linear model, static model and hysteresis model $[15 \div 17]$.

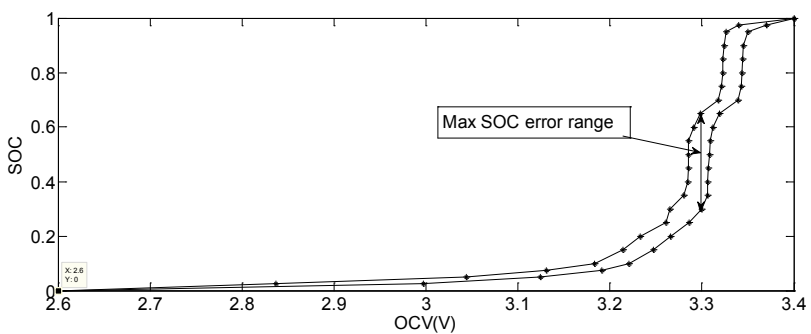

(a) $S O C-O C V$ curve

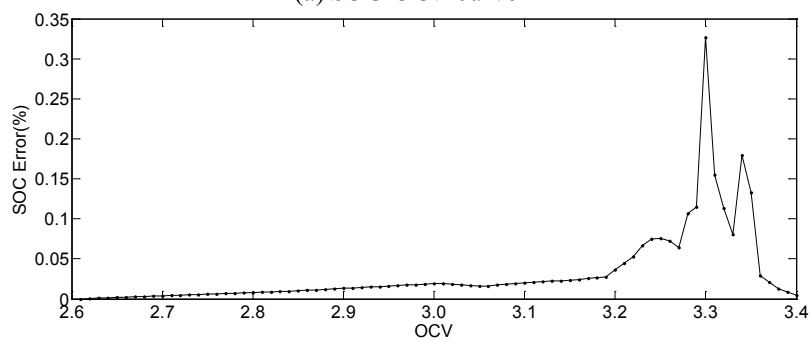

(b) SOC error curve

Figure 6 The influence of hysteretic characteristics

\subsection{Linear models}

As shown in Fig. 7, linear model regards the battery as a large capacitor $\mathrm{C}$, and $U_{o c}$ represents capacitor voltage. Meanwhile, a small resistor $R_{0}$ is cascaded with the capacitor. The resistor is called the battery's "internal resistor" and changes with the ambient temperature and the life of batteries [18].

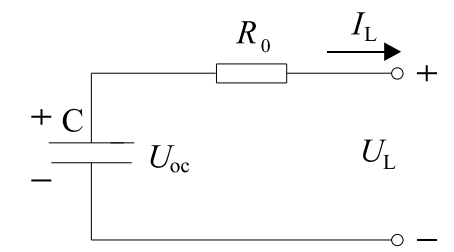

Figure 7 Equivalent circuit of liner model

\subsection{Relaxation model}

This battery model takes relaxation characteristic [19] into consideration. Relaxation characteristic is the phenomenon of battery $O C V$ slow return to equilibrium after a period of time charging or discharging, which can be expressed by a series of RC networks. The more $\mathrm{RC}$ networks, the closer to true $O C V$. Compared with linear model, it uses controllable voltage source instead of large capacitor to represent electromotive force, and the voltage is a function of $S O C$. Fig. 8 shows the relaxation model.

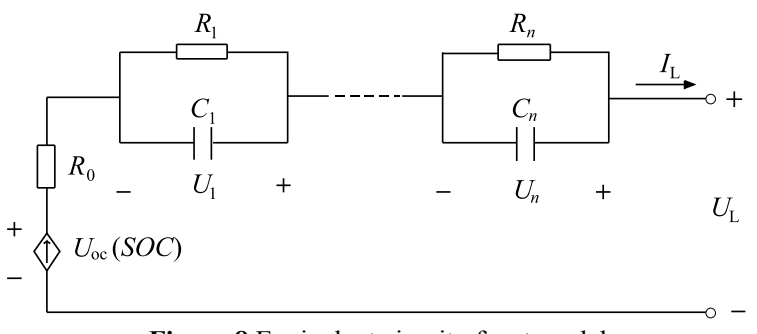

Figure 8 Equivalent circuit of rest model

\subsection{Hysteresis model}

Hysteresis model is the battery model that takes hysteresis characteristic into consideration.

The basic idea to describe the hysteresis characteristics of this paper is to propose a mathematical model that successively approaches the upper curve $O C V_{\text {Charge }}$ when the cell is charging and approach the lower one $O C V_{\text {Discharge }}$ when it discharges [20]. The following models are chosen after many times comparison:

The second order RC hysteresis equivalent circuit model is chosen by considering model precision, complexity and chosen LiFePO4. The model is shown in Fig. 10 .

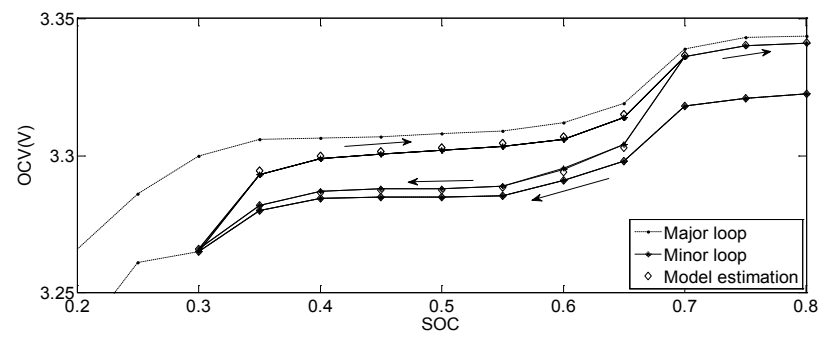

Figure 9 Estimate curve of hysteresis characteristics

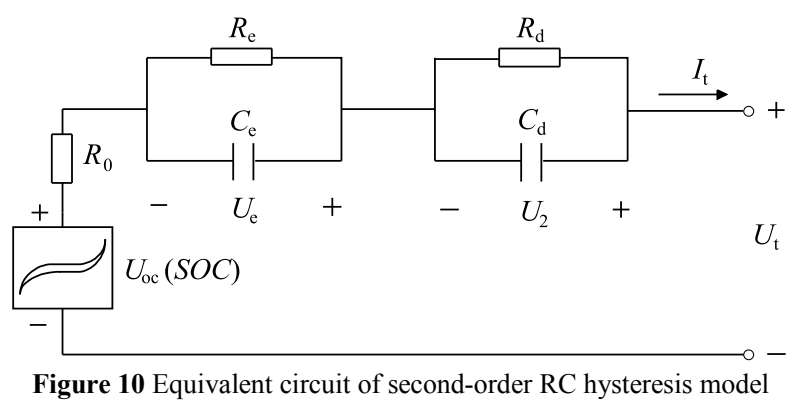

$U_{\text {oc }}(S O C)$ is lithium-ion battery $O C V$ to describe the hysteresis characteristics of the battery; $U_{\mathrm{t}}$ is terminal voltage; $I_{\mathrm{t}}$ is terminal current; $R_{0}$ is internal resistance; $R_{\mathrm{e}}$, $C_{\mathrm{e}}$ and $R_{\mathrm{d}}, C_{d}$ are used to describe relaxation characteristic of the battery. All above parameters of lithium-ion battery change with the changing of SOC.

$$
\frac{\mathrm{d} O C V}{\mathrm{~d} S O C}=\left\{\begin{array}{l}
\frac{\mathrm{d} O C V_{\text {Charge }}}{\mathrm{d} S O C}+\eta\left(O C V_{\text {Charge }}-O C V\right), \frac{\mathrm{d} S O C}{\mathrm{~d} t} \geq 0 \\
\frac{\mathrm{d} O C V_{\text {Discharge }}}{\mathrm{d} S O C}+\eta\left(O C V-O C V_{\text {Discharge }}\right), \frac{\mathrm{d} S O C}{\mathrm{~d} t}<0
\end{array}\right.
$$




$$
\eta=\left\{\begin{array}{l}
\frac{1}{S O C(k+1)} \times \frac{O C V(k+1)-O C V_{\mathrm{c}}(k+1)}{O C V_{\mathrm{c}}(k)-O C V(k)}, \frac{\mathrm{d} S O C}{\mathrm{~d} t} \geq 0 \\
\frac{1}{S O C(k+1)} \times \frac{O C V(k+1)-O C V_{\mathrm{d}}(k+1)}{O C V(k)-O C V_{\mathrm{d}}(k)}, \frac{\mathrm{d} S O C}{\mathrm{~d} t}<0
\end{array}\right.
$$

$\eta$ is adjustment coefficient.

According to Eq. (3), we can obtain Eq. (4). Data of test 2 are utilized in Eq. (4) and Averaging, we can obtain: $\eta=9,985$.

In order to verify the accuracy of the models, results are shown in Fig. 9. Even if the demonstrated hysteresis model is very simple, the $O C V$ can be simulated accurately with deviations of less than $2 \mathrm{mV}$.

In order to improve the precision of model, the recursive least squares method is used to estimate the above parameters of the equivalent circuit model. The estimation results based on a pulse discharge data are shown in Fig. 11.

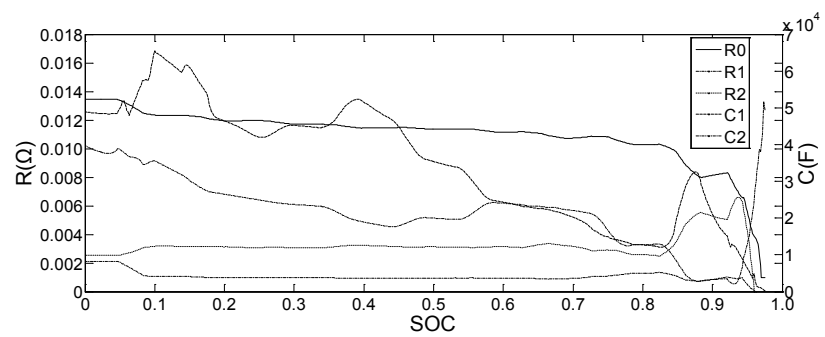

Figure 11 Parameters identification curve

\section{SOC estimation of lithium-ion battery based on the hysteresis model}

There are two disadvantages in the process of EKF state estimation:

1) When the high-order Taylor expansion term of nonlinear function cannot be ignored, linearization will produce bigger system error, and even make the filter unstable.

2) Jacobin matrix is needed to calculate at each filter cycle, and this will greatly increase the computational complexity of filtering estimation.

$$
\begin{aligned}
& \left(\begin{array}{c}
S O C(k+1) \\
U_{\mathrm{e}}(k+1) \\
U_{\mathrm{d}}(k+1)
\end{array}\right)=\left(\begin{array}{ccc}
1 & 0 & 0 \\
0 & \mathrm{e}^{-\frac{T}{\tau_{\mathrm{e}}}} & 0 \\
0 & 0 & \mathrm{e}^{-\frac{T}{\tau_{\mathrm{d}}}}
\end{array}\right) \times\left(\begin{array}{c}
S O C(k) \\
U_{\mathrm{e}}(k) \\
U_{\mathrm{d}}(k)
\end{array}\right)+ \\
& \left(\begin{array}{c}
-\frac{\eta T}{Q_{n}} \\
R_{\mathrm{e}}\left(1-\mathrm{e}^{-\frac{T}{\tau_{\mathrm{e}}}}\right) \\
R_{\mathrm{d}}\left(1-\mathrm{e}^{-\frac{T}{\tau_{\mathrm{d}}}}\right)
\end{array}\right) I_{\mathrm{t}}(k)+w_{k}, \\
& U_{\mathrm{t}}(k)=U_{\mathrm{oc}}(S O C(k))-U_{\mathrm{e}}(k)-U_{\mathrm{d}}(k)-R_{0} I_{\mathrm{t}}(k)+v_{k}
\end{aligned}
$$

This paper uses another kind of Kalman filter nonlinear method - Cubature Kalman Filter (CKF) [18] to estimate lithium-ion battery SOC. It uses the same weight cubature points to approximate posterior distribution of optimal state $[19,20]$. CKF is suitable to solve nonlinear state estimation problems from low dimension to high dimension, and its estimation precision can reach second order Taylor precision at least.

Regarding $S O C, U_{\mathrm{e}}$ and $U_{\mathrm{d}}$ as state variables, $I_{\mathrm{t}}$ as input, $U_{\mathrm{t}}$ as output, the discretization state equation (5) and observation equation (6) is obtained. Wher $\tau_{\mathrm{e}}$ is coulomb efficiency. $\tau_{\mathrm{e}}$ is rated capacity of the battery; $T$ is sampling period; $\tau_{\mathrm{e}}$ and $\tau_{\mathrm{d}}$ are time constant of $\mathrm{RC}$ networks, $\tau_{\mathrm{e}}=R_{\mathrm{e}} C_{\mathrm{e}}, \tau_{\mathrm{d}}=R_{\mathrm{d}} C_{\mathrm{d}} ; I_{\mathrm{t}}(k)$ is current of $\mathrm{k}$ moment; $w_{k}$ and $v_{k}$ are unrelated gaussian white noise.

1) Initialization:

$\hat{x}_{0}=[\operatorname{SOC}(0) \quad 0 \quad 0], \hat{P}_{0}=E\left[\left(x_{0}-\hat{x}_{0}\right)\left(x_{0}-\hat{x}_{0}\right)^{\mathrm{T}}\right]$.

2) Forecast update:

$P_{k}=S_{k} S_{k}^{T}, \xi_{i, k}^{C K F}=S_{k} \xi_{i}+\hat{x}_{k}$

$\gamma_{i, k+1 \mid k}^{C K F}=f\left(\xi_{i, k}^{C K F}, u_{k}\right)+\hat{q}_{k}$

$\hat{x}_{k+1 \mid k}=\frac{1}{L} \sum_{i=1}^{L} \gamma_{i, k+1 \mid k}^{C K F}=\frac{1}{L} \sum_{i=1}^{L} f\left(\xi_{i, k}^{C K F}, u_{k}\right)+\hat{q}_{k}$

$P_{k+1 \mid k}=\frac{1}{L} \sum_{i=1}^{L}\left(\gamma_{i, k+1 \mid k}^{C K F}-\hat{x}_{k+1 \mid k}\right)\left(\gamma_{i, k+1 \mid k}^{C K F}-\hat{x}_{k+1 \mid k}\right)^{T}+\hat{Q}_{k}$

$=\frac{1}{L} \sum_{i=1}^{L} \gamma_{i, k+1 \mid k}^{C K F} \gamma_{i, k+1 \mid k}^{C K F}{ }^{T}-\hat{x}_{k+1 \mid k} \hat{x}_{k+1 \mid k}^{T}+\hat{Q}_{k}$

3) Measurement update:

$P_{k+1 \mid k}=S_{k+1 \mid k} S_{k+1 \mid k}^{T}$

$\xi_{i, k+1 \mid k}^{C K F}=S_{k+1 \mid k} \xi_{i}+\hat{x}_{k+1 \mid k}$

$\chi_{i, k+1 \mid k}^{C K F}=h\left(\xi_{i, k+1 \mid k}^{C K F}, u_{k+1}\right)+\hat{r}_{k+1}$

$\hat{z}_{k+1 \mid k}=\frac{1}{L} \sum_{i=1}^{L} \chi_{i, k+1 \mid k}^{C K F}=\frac{1}{L} \sum_{i=1}^{L} h\left(\xi_{i, k+1 \mid k}^{C K F}, u_{k+1}\right)+\hat{r}_{k+1}$

$P^{\mathrm{Z}}{ }_{k+1 \mid k}$

$=\frac{1}{L} \sum_{i=1}^{L}\left(\chi_{i, k+1 \mid k}^{C K F}-\hat{z}_{k+1 \mid k}\right)\left(\chi_{i, k+1 \mid k}^{C K F}-\hat{z}_{k+1 \mid k}\right)^{T}+\hat{R}_{k+1}$

$=\frac{1}{L} \sum_{i=1}^{L} \chi_{i, k+1 \mid k}^{C K F} \chi_{i, k+1 \mid k}^{C K F}-\hat{z}_{k+1 \mid k} \hat{z}_{k+1 \mid k}^{T}+\hat{R}_{k+1}$

$=\frac{1}{L} \sum_{i=1}^{L} \chi_{i, k+1 \mid k}^{C K F} \chi_{i, k+1 \mid k}^{C K F}-\hat{z}_{k+1 \mid k} \hat{z}_{k+1 \mid k}^{T}+\hat{R}_{k+1}$

$P_{k+1 \mid k}^{x z}=\frac{1}{L} \sum_{i=1}^{L}\left(\xi_{i, k+1 \mid k}^{C K F}-\hat{x}_{k+1 \mid k}\right)\left(\chi_{i, k+1 \mid k}^{C K F}-\hat{z}_{k+1 \mid k}\right)^{T}$

$=\frac{1}{L} \sum_{i=1}^{L} \xi_{i, k+1 \mid k}^{C K F} \chi_{i, k+1 \mid k}^{C K F}-\hat{x}_{k+1 \mid k} \hat{z}_{k+1 \mid k}^{T}$ 
4) State updates:

$W_{k+1}=P_{k+1 \mid k}^{x z}\left(P_{k+1 \mid k}^{z}\right)^{-1}$

$\hat{x}_{k+1}=\hat{x}_{k+1 \mid k}+W_{k+1}\left(z_{k+1}-\hat{z}_{k+1 \mid k}\right)$

$P_{k+1}=P_{k+1 \mid k}-W_{k+1} P_{k+1 \mid k}^{z} W_{k+1}^{T}$.

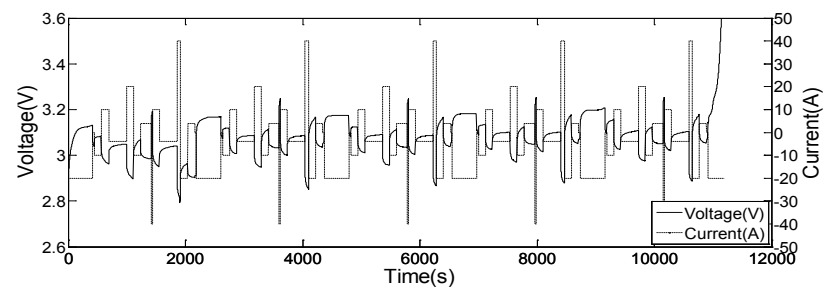

(a) Charging DST condition

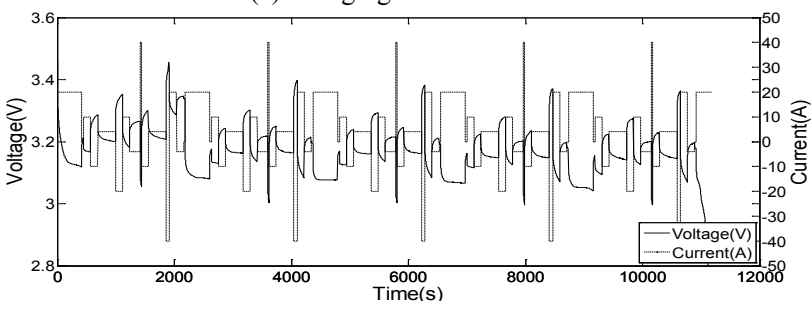

(b) Discharging DST condition

Figure 12 Terminal voltage and current in DST conditions
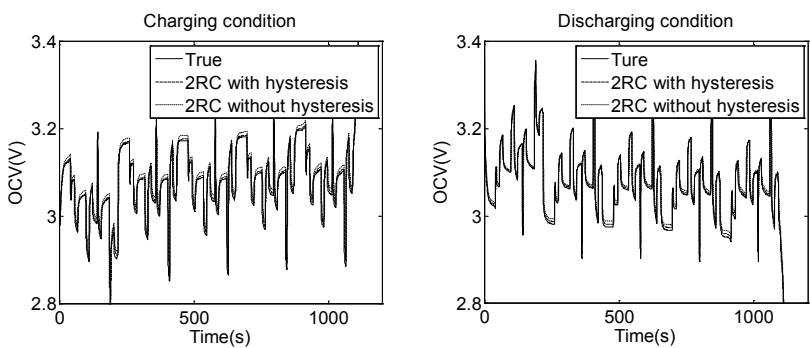

(a) True voltage and estimated voltage
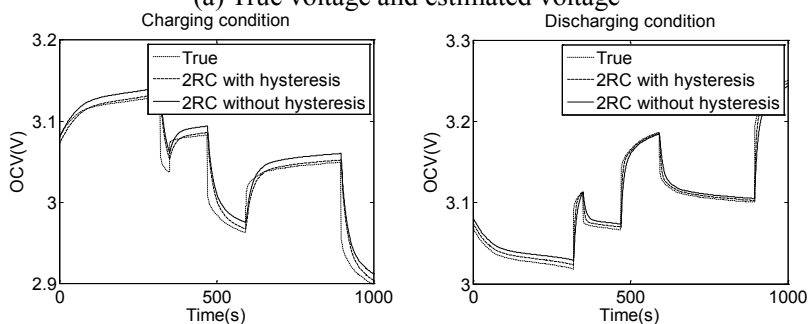

(b) Local amplification of true voltage and estimated voltage Charging condition
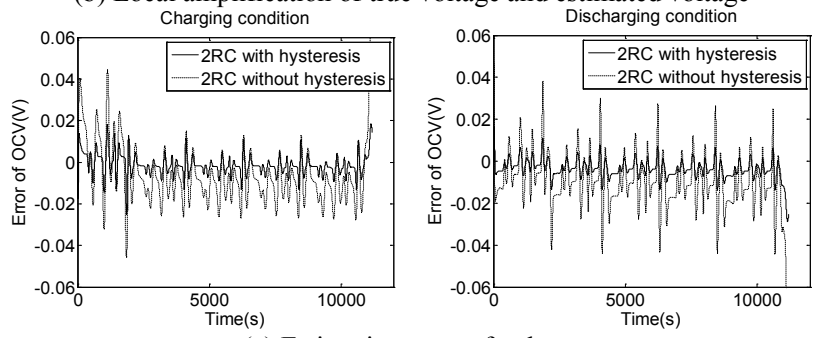

(c) Estimation error of voltage

Figure 13 The results of model validation in DST conditions

\section{Result validations}

The lithium-ion battery hysteresis model and CKF algorithm are verified with two DST conditions, which are charging condition and discharging conditions respectively. Both of two DST conditions have 5 testing cycles, in which every testing cycle consists of 14 steps. Fig. 12 shows the terminal voltage and current of lithium ion battery of two DST conditions.

\subsection{Model validation}

Fig. 13 shows the estimation value of lithium-ion battery terminal voltage and estimation error of equivalent model with and without considered hysteretic characteristics. The results of the two conditions can be found by utilized battery current and voltage data in the hysteresis models shown in Fig. 10.
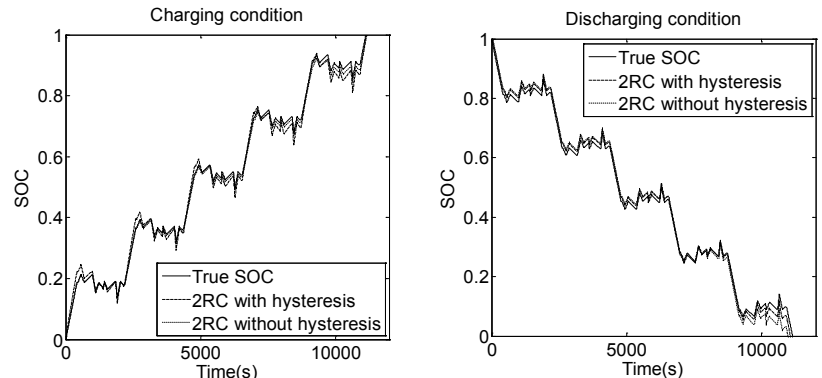

(a) True $S O C$ and estimated $S O C$
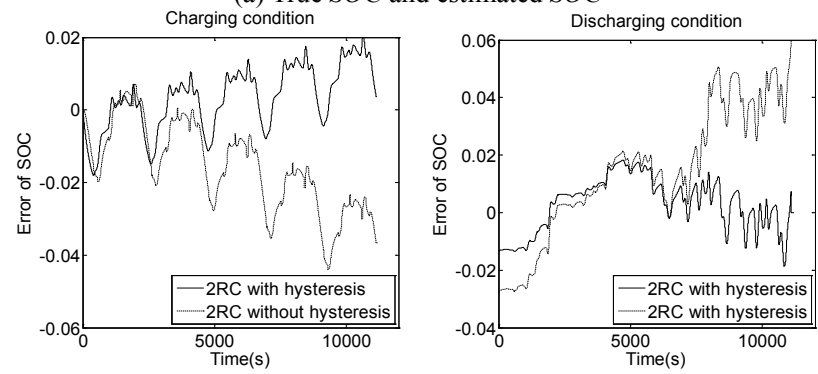

(b) The error of SOC estimation

Figure 14 The results of algorithm validation in DST condition
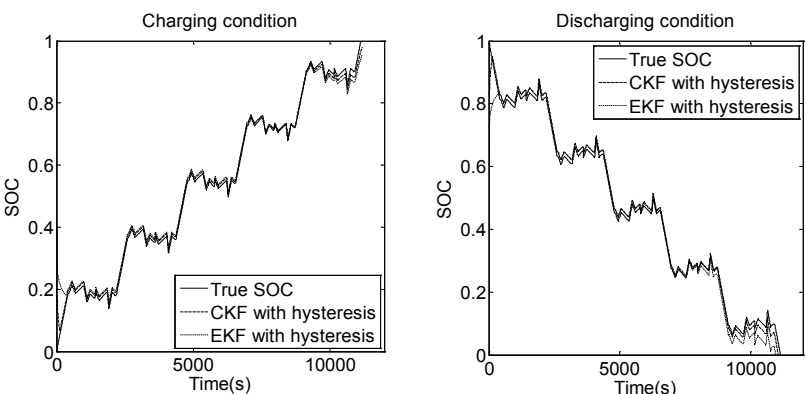

(a) True SOC and estimated SOC
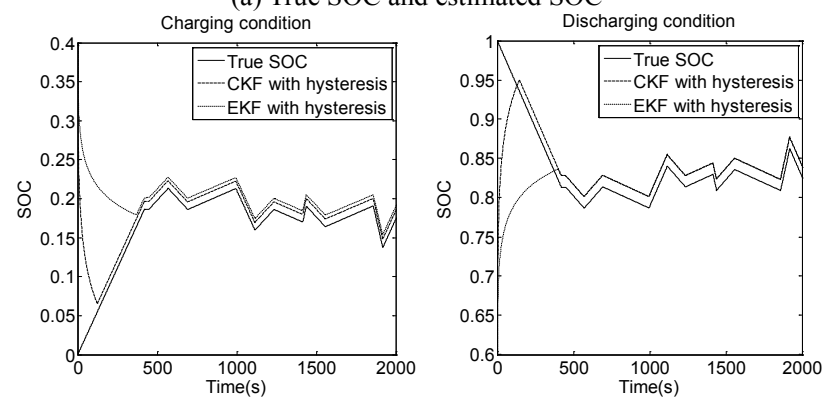

(b) Local amplification of true SOC and estimated SOC

Figure 15 The results of algorithm validation in DST condition with wrong initial condition

As shown in Fig. 13(c), the terminal voltage estimation error is within $0,02 \mathrm{~V}$ when considering hysteresis characteristics. This means that the second- 
order RC hysteresis model can track the dynamic characteristics of lithium-ion battery more accurately even in the condition of the severe changes of current.

\subsection{Algorithm verification}

The experiment results are shown in Fig. 14 by Using $\mathrm{CKF}$ to estimate the battery SOC. All the truth value of $S O C$ is based on an ampere-hour integral method. Fig. 14(c) shows that SOC estimation errors are less than $2 \%$ and $5 \%$ respectively, which explains CKF algorithm can accurately estimate the battery $S O C$ even if model error is considerable. It can accurately track the actual value of $S O C$, which shows CKF has good robustness.

In order to compare the speed of CKF and EKF converging to the true value with wrong initial value, initial $S O C$ of charging and discharge conditions is set to 0,4 and 0,6 respectively. As shown in Fog. 15, CKF converges to true $S O C$ faster than EKF, and has better dynamic interference resistance as well.

\section{Conclusions}

This paper analyses the influence of hysteresis characteristics to battery $S O C$ estimation quantitatively. A simple and feasible equivalent hysteresis model is established for charging and discharging experiments. In addition, $\mathrm{CKF}$ algorithm is used to estimate battery $S O C$. As a result, the advantages of the model and algorithm can be verified.

\section{$7 \quad$ References}

[1] Jiang, Ruibin; Tan, Ligang. The Development and the Challenges of Electric Vehicles. // Mechanical Engineer. 2, (2009), pp. 23-25.

[2] Lin, Chengtao; Wang, Junping; Chen, Quanshi. Methods for state of charge estimation of EV batteries and their application. // Battery Bimonthly. 5, (2004) pp. 376-378.

[3] Liu, Yanli; Dai, Sheng; Cheng, Ze; Zhu, Lewei. Estimation of State of Charge of lithium-ion Battery Based on Finite Difference Extended Kalman Filter. // Journal of electrotechnics. 29, 1(2014), pp. 221-228.

[4] Xia, Chaoying; Zhang, Shu; Sun, Hongtao. A strategy of estimating state of charge based on extended Kalman filter. // Power Technology. 5, (2007), pp. 414-417.

[5] Tan, Xiaojun. The design of Electric vehicle power battery management system. // Sun yat-sen university press, (2011).

[6] Ala, Al-Haj Hussein; Nasser, Kutkut; Issa, Batarseh. A Hysteresis Model for a Lithium Battery Cell with Improved Transient Response. // Applied Power Electronics Conference and Exposition (APEC) / 2011, pp. 1790-1794.

[7] Hussein, H. A. H.; Kutkut, N.; Batarseh, I. A hysteresis model for a lithium battery cell with improved transient response // Applied Power Electronics Conference and Exposition (APEC), 2011 Twenty-Sixth Annual IEEE / 2011, pp. 1790-1794.

[8] Trapanese, M.; Franzitta, V.; Viola, A. The Jiles Atherton model for description of hysteresis in lithium battery // Applied Power Electronics Conference and Exposition (APEC), 2013 Twenty-Eighth Annual IEEE / 2013, pp. 2773-2775.

[9] Tian, Tian; Li, Xiaozun; Li, Hongmei. Modified modeling and SOC estimation of LiFePO4 Li-ion battery // Journal of Hefei University of Technology (Natural Science). 9, (2012), pp. 1192-1195+1252.
[10] Roscher, M. A.; Sauer, D. U. Dynamic electric behavior and open-circuit-voltage modeling of LiFePO4-based lithium-ion secondary batteries // Journal of Power Sources. 19, 1(2011), pp. 331-336. DOI: 10.1016/j.jpowsour.2010.06.098

[11] Baronti, F.; Zamboni, W.; Femia, N. et al. Experimental analysis of open-circuit voltage hysteresis in lithium-ironphosphate batteries // Industrial Electronics Society, IECON 2013-39th Annual Conference of the IEEE / 2013, pp 6728-6733.

[12] Chen, Quanshi; Lin, Chengtao. Summarization of Studies on Performance Models of Battery for Electric Vehicle // Automotive Technology. 3, (2005), pp. 1-5.

[13] Di Domenico, D.; Fiengo, G. Lithium-ion battery state of charge estimation with a Kalman filter based on electrochemical model. // Control Applications (CCA) / (2008), pp. 702-707.

[14] Kaizheng, Fang; Daobin, Mu; Shi, Chen et al. A Prediction Model Based on Artificial Neural Network for Surface Temperature Simulation of Nickel-metal Hydride Battery during Charging. // Journal of Power Sources. (2012), pp. 378-382.

[15] Eichi, H. R.; Chow, M. Y. Modeling and analysis of battery hysteresis effects. // Energy Conversion Congress and Exposition (ECCE) / 2012, pp. 4479-4486.

[16] Johnson, V. H. Battery Performance Models in Advisor // Journal of Power Sources. (2002), pp. 321-329. DOI: 10.1016/S0378-7753(02)00194-5

[17] Kroeze, R. C.; Krein, P. T. Electrical Battery Model for Use in Dynamic Electric Vehicle Simulations. // Power Electronics Specialists Conference (PESC) / 2008, pp. 1336-1342.

[18] Wang, Xiaoxu; Pan, Quan; Huang, He et al. Overview of deterministic sampling filtering algorithms for nonlinear system. // Control and Decision. 27, 6(2012), pp. 801-812.

[19] Ding, Jialin; Xiao, Jian. Design of adaptive cubature Kalman filter based on maximum a posteriori estimation. // Control and Decision. 29, 2(2014), pp. 327-334.

[20] Zhao, Liqiang; Luo, Dacan; Wang, Jianlin et al. Adaptive Strong Tracking Kalman filtering algorithm. // Journal of Beijing University of Chemical Technology. (2013), pp. 98103.

\section{Authors' addresses}

Ze Cheng, Associate Professor

School of Electrical Engineering \& Automation of Tianjin University, 300072 Tianjin, China E-mail: chengze@tju.edu.cn

\section{Li Wang, Master}

School of Electrical Engineering \& Automation of Tianjin University, 300072 Tianjin, China E-mail:wlxhxh@163.com

Jiguang Liu

School of Electrical Engineering \& Automation of Tianjin University, 300072 Tianjin, China E-mail: zdhljg@tju.edu.cn

Jikao Lv, Master

School of Electrical Engineering \& Automation of Tianjin University, 300072 Tianjin, China E-mail: lvjikao@126.com 